\title{
Assessment of ameliorative effects of aqueous extracts of Moringa oleifera on acetaminophen -induced nephrotoxicity in rats
}

\author{
Al Tayib O. A. and El Badwi S. M. ${ }^{2}$ \\ ${ }^{1}$ College of Dentistry, King Saud University, Riyadh, Saudi Arabia. ${ }^{2}$ Department of Pharmacology and \\ Toxicology, Faculty of Veterinary Medicine, University of Khartoum, Sudan.
}

\begin{abstract}
The ameliorative effects of Moringa oleifera L. (M. oleifera) is well known to modulate and enhance several immune parameters. The present study investigates the efficacy of the aqueous extract leaves of the M. oleifera on prevention of acetaminophen (APAP) induced acute renal injury in Wistar rats. Thirty albino rats were arranged randomly into 5 groups of 5 rats. Group 2 served as intoxicated group and received APAP (200 $\mathrm{mg} / \mathrm{kg}$ ). Group 3, 4 and 5 received APAP $(200 \mathrm{mg} / \mathrm{kg})+$ M. oleifera at doses 250,500 and $1000 \mathrm{mg} / \mathrm{kg}$, respectively. While first group was served as control rats group. All treatment was given orally to animals for 14 days. Clinical signs were observed regularly and rats were sacrificed and bloods and tissue samples were collected for biochemical and histological analysis. Biochemical results showed that $M$. oleifera protected the toxic remarks caused by APAP when decrease the elevated levels of serum creatinine, blood urea, cholesterol and lipids, while increases the plasma levels of total protein and albumin. Also, the nephroprotective effects of extracts was strongly correlated with decreased damage of the renal cellular damage, as evidenced by histological findings when compared to the group treated with APAP. Our findings provide evidence to demonstrate that aqueous extract of M. oleifera has a potent nephroprotective effect on APAP-induced kidney injury in rats. It is proposed that the action of plant is through its antioxidative and its ability to restoration or promoting glutathione (GSH) through decrease in the biotransformation of APAP via cytochrome P-450 pathway.
\end{abstract}

Keywords: M. oleifera L.; Acetaminophen; nephros; kidney; P-450; GSH; rats

\section{INTRODUCTION}

Nephrotoxicity from Greek: nephros, "kidney" is a poisonous effect of some substances, both toxic chemicals and medication, on the kidneys [1]. However, nephroprotective agents are the substances which possess protective activity against Nephrotoxicity. Indeed, the kidney is considered as one of the vital organ in health and disease, it received $25 \%$ of the cardiac output and have high oxygen needs, largely caused by the energy required for the reabsorption mechanisms [2]. Moreover, it plays a vital role in regulating various physiological processes in the body as water and electrolyte homeostasis, maintenance of plasma osmolarity, acid-base balance, and the production and secretion of hormones [3,4]. Due to the fact that, drug elimination was occurs mainly via the kidneys and thus several previous reports suggested the toxic effects of environmental contaminants including drugs might response to alter the functions of the kidney [5, 6]. Nevertheless, as kidney function declines, each of the kidney's functions is affected and/or decline at different rates, including clearance of drugs and their metabolites.

Acetaminophen (APAP) is an effective analgesic and antipyretic prescription medications alternative to aspirin and the recommended doses of this drug considered safely, however, its overdoses and/or chronic uses associated with liver and kidney damages in both humans and animals [7]. APAP causing cell injuries has been well studied in several scientific literature reports; following APAP ingestion a majority of the drug metabolized by sulphation and glucuronidation to unreactive metabolites. However, small fraction remained metabolized by the cytochrome P-450 system (CYP450) to the toxic metabolites N-acetyl -benzoquinoneimine (NAPQI) which involved in its toxic effects [8]. Therefore, APAP toxicity is mediated by the activity of its reactive metabolite NAPQI, which under normal conditions is detoxified through conjugation with intracellular glutathione (GSH) to form mercapturic acid [9]. Thus, overdose of APAP will saturate the conjugation pathways of GSH and cause depletion of cellular GSH. It is well-known that the mechanism of metabolism of APAP was subsequently leads to reduced capacity of GSH to detoxify NAPQI and thus the increased level of NAPQI oxidizes tissue macromolecules, such as lipids or protein thiols, and alters the homeostasis of calcium after depleting glutathione which leads to oxidative damage and thus enhances cellular injuries and organ dysfunction, including renal damage [10]. In correlations, a study suggests that APAP overdose induces renal oxidative stress elucidated when lipid peroxidation rise and antioxidant enzymes levels decrease [11]. 
Over the past two and a half decades several reports suggested the health properties of the Moringa oleifera L. (M. oliefera) tree [12]. M. oleifera is belonging to Moringaceae family; it is commonly known as drumstick or horseradish tree. It is indigenous to Northwest India but, at present, it is widely distributed in the tropics throughout the Pacific, West Africa, as well as Central America and the Caribbean [13]. Nevertheless, $M$. oleifera is referred to as a miracle tree of significant socio economic importance because of its potential to improve nutrition boosts food security and foster rural development pharmacological and industrial applications [12]. However, a list of benefits of $M$. oleifera plants' bioactive compounds to human health includes antimicrobial, anti-oxidants, anticancer, antihypertension, and treatment of diabetes [14, 15]. Additionally, in the absence of reliable kidney protective drugs in modern medicine; herbal drugs play a major role in the treatment of renal disorders. Moreover, scientific literatures have prescribed various medicinal plants and/or herbs for the cure of renal disorders which have curative properties due to the presence of various complex chemical substances possessing nephroprotective activities $[16,17]$. It is well-known that folkloric medicinal and/or plant extracts are imports a variety of renal protective plant species for uses in traditional medicine [18]. Furthermore, traditionally $M$. oleifera is used for the treatment renal disorders [13, 19]. Though the traditional treatment of the $M$. oleifera leaves extract for renal disorders, and thus its nephroprotective activity has not yet been investigated. Considering these earlier results, we investigated the role of $M$. oleifera aqueous extracts when considering the effect of acetaminophen on renal damages induced by. Therefore, the current study was undertaken to examine the possible beneficial effect of oral administration of aqueous extracts of $M$. oleifera leaves on APAP-induced nephrotoxicity in Wistar rats, nevertheless, changes in biochemical as well as blood and serum concentration levels and histopathological transposition were considered for assessing its nephroprotective characteristic.

\subsection{Animals}

\section{MATERIALS AND METHODS}

Albino Wistar rats $(230 \pm 10 \mathrm{~g})$ were obtained from the National Center for Research, Khartoum, Sudan. The animals used in the study were housed under standard conditions in cages at the Department of Pharmacology and Toxicology, Faculty of Veterinary Medicine; University of Khartoum and allowed to acclimate for at least one week. The rats were housed in groups ( 5 rats per cage) in a light and temperaturecontrolled room (12/12-h light-dark cycle, $\left.21 \pm 2^{\circ} \mathrm{C}\right)$ with free access to food and water. The experiments were approved by the Institutional Animal Care Committee.

\subsection{Preparation of extract}

Fresh leaves of M. oleifera plant were collected in March 2014 from Al-Mugran area, Khartoum state, Sudan. The plant leaves of $M$. oleifera were identified by specialist at the Botany Unit of the Medicinal and Aromatic Plants Research Institute (MAPRI), Khartoum, Sudan. The plant leaves was allowed to dry at room temperature in the laboratory for a period of 14 days. The coarse plant was powdered in a blender and subjected to successive aqueous extraction. The coarse powder were soaked in boiling distilled water and left for two days at room temperature. The mixture was filtered through a filter paper. The filtrate was centrifuged and cooled over night in dishes at $4^{\circ} \mathrm{C}$. The yields percentages were calculated and the concentrated extract was freezing and kept in the refrigerator until used. The powdered leaves weighted $500 \mathrm{~g}$ and the extract weight was $30 \mathrm{~g}$.

\subsection{Administration and dosage rates}

Post adaptive period, rats divided according to weight into five equal groups, each of five rats: Group 2 induction control given APAP $(200 \mathrm{mg} / \mathrm{kg}$ ) as APAP control. Group 3, 4 and 5 were received (APAP $200 \mathrm{mg} / \mathrm{kg}$ ) orally and treated with aqueous extract of $M$. oleifera leaves as nephroprotective agent at $(250,500$ and $1000 \mathrm{mg} / \mathrm{kg}$ ) respectively, for 14 days orally. Group 1 received distilled water for 14 days and acted as a control group and except this group; treatments were given to all groups orally with the help of feeding canula.

\subsection{Sample collection and blood parameters}

At the end of the experimental period, rats were placed in their metabolic cages and all rats were anesthetized with light diethyl ether and $(2 \mathrm{~mL})$ of blood was collected from orbital plexus and placed into blood tubes for hematological investigation and serum analysis. An automated cell counter (System LX-21N) was used to analyze blood for hematological parameters, to determine the blood concentrations as: $\mathrm{Hb}, \mathrm{RBC}$, $\mathrm{PCV}, \mathrm{MCV}$ and MCHC. For serum, blood was allowed to clot and then centrifuged at $5000 \mathrm{rpm}$ for $10 \mathrm{~min}$ at room temperature and samples were aliquoted and stored at $\left(-80^{\circ} \mathrm{C}\right)$ for further analysis of biochemical parameters using commercial available kits according to manufacturer's instruction. Serum samples were analyzed for the concentrations of creatinine, urea, total cholesterol, lipids, total protein and albumin applying colorimetric procedures using commercial kits (Randox Laboratories LTD., UK). 


\subsection{Histological analysis}

Kidney specimens from all groups of rats were collected immediately after they were sacrificed. Tissues were fixed in $10 \%$ buffered normal saline, processed well and then embedded in paraffin wax. Tissue sections of $5 \mu \mathrm{m}$ were obtained and stained with Hematoxylin and Eosin (H\&E). The sections examinations were performed under a light microscope.

\subsection{Statistical methods}

All results were expressed as mean \pm SE. One-way Analysis of Variance (ANOVA) was used for the statistical analysis of data. Duncan's multiple range tests was used for determining the results significance. A probability value of $(\mathrm{P}<0.05)$ was considered as significant.

\subsection{Biochemical results}

\section{RESULTS}

Table 1 showed the effect of $M$. oleifera aqueous extract on serum constituents of rats administrated with APAP. The concentration of blood urea, serum creatinine, cholesterol and total lipids were significantly higher, while total protein and albumin levels were significantly decreased in rats group received APAP when compared to the control (Group-1). However, in all groups which co-treatment with M. oleifera and APAP recorded lower concentration of urea, creatinine, cholesterol and total lipids as well as a significant increase in total protein and albumin levels when compared to Group 2 and almost near the normal values when compared to the control group untreated rats.

\subsection{Hematological results}

Hematological findings are presented in Table 2. At day 14 there was significant decrease in $\mathrm{RBC}, \mathrm{Hb}$, $\mathrm{PCV}$ and MCV values and significant increase in MCV and MCHC in APAP treated rats (Group 2) compared to the control. In contrast, the group of rats received APAP concurrent with administration of M. oleifera at 250, 500 and $1000 \mathrm{mg} / \mathrm{kg}$ showed significantly improved evidenced by increase in RBC, $\mathrm{Hb}$ and PCV values and significant decreased in MCV and MCHC values compared to APAP group.

\subsection{Histological results}

Figure 1 (a-d) showing the kidneys of rats treated with/without APAP and M. oleifera aqueous extract. Histopathologically kidney in the control rats showed no abnormalities, while in APAP treated rats, kidney sections showed severe necrosis of the renal tubules, shrinkage of glomeruli and fatty change (Figure 1-a). Kidney section of rats treated with M. oleifera on APAP are presented in Figure (1-b) showed necrosis, hemorrhage and shrinkage of glomeruli. Also, kidney section in Figure (1-c) showed mild necrosis and hemorrhage, while Figure (1-d) showed lymphocyte infiltration of the glomeruli.

\section{DISCUSSION}

APAP is one of the most well known anti pyretic and analgesic agents had been used worldwide. In recent time, the safety of APAP at therapeutic dose has generated a lot of hot debate. It is toxicity mediated by the activity of its reactive toxic metabolite NAPQI, which is detoxified by intracellular GSH [20]. Therefore, increased level of free NAPQI mediates oxidative damage and thus enhances cellular injuries and organ dysfunction, including renal damage [21]. However, following APAP over doses toxicities, an alteration in biochemical levels, blood profiles, kidney functions and histological features were reported and then taken as an index of APAP nephrotoxicity in experimental rats [22].

In our work, APAP -induced nephrotoxicity in Wistar rats is well evidenced via an elevated levels occur in the sera of creatinine, urea, cholesterol followed by a depletion of total proteins and albumin sera. Our results in this study were agree with a previous results suggested all that alterations in sera levels when analysis were taken as an evidence of APAP causing nephreotoxicity in rats models [23, 24]. Furthermore, Vigila and Baskaran [25], noticed that, in rats' nephrotoxicity and renal diseases, blood urea and creatinine increased, while proteins and albumin were significantly reduced. Our findings were also in line with an earlier report state that sera levels of creatinine and urea in kidney diseases will rise because the rate of production exceeds the rat of clearance due to the defect in kidney function [26]. Indeed, supporting to this, the disturbance of the renal functions was further reflected on its defective re-absorptive capacity of albumin and protein in plasma levels, which led to their appearance in high quantities in the urine and thus decreased in sera levels [27]. In addition, diminution of total protein and albumin associated with augmented serum urea and creatinine was cons indicating a further indication of kidney glomerular damage after APAP injection [28]. Thus, significant diminution in protein and albumin levels in the current study confirmed renal damage in rats following APAP over dosing. Although, it is evident from prior clinical data that elevations in the cholesterol and triglyceride plasma levels have been demonstrated to be reflects progression of renal disease in a variety of animal models and man $[29,30]$. Similarly, elevated levels of serum creatinine, urea, total cholesterol and triglycerides, 
followed by decrease in total protein and albumin, are indicative of cellular leakage and loss of functional integrity of cell membrane in liver damage induced by APAP [31].

Our results in this study showed that, treatment of rats with $M$. oleifera aqueous extracts doses of 250 , 500 and $100 \mathrm{mg} / \mathrm{kg}$ reduced the alteration levels of biochemical parameters induced by APAP and these results suggest the possibility of extracts to have ability to stabilize kidney dysfunction in rat during renal injury with APAP. Indeed, aqueous extracts of $M$. oleifera may reduce the alteration sera levels induced by APAP; due to its ability to stabilize kidney dysfunction in rats following APAP overdoses and that might be due to the highly antioxidant activities found on this plant and thus successfully decreasing oxidations which response of causing nephrotoxicity [32]. Increase levels of free NAPQI following the depletion of cellular GSH levels will enhances cellular injuries and cause renal dysfunction, however, recently report by Fakurazi and co-workers found that aqueous extract of $M$. oleifera leaves against APAP toxicity is due to its ability to restoration or promoting GSH through decrease the biotransformation of APAP via cytochrome P450 pathway, and thus inhibits toxic metabolism of APAO to free NAPQI which leads to GSH depletion [33].

Other antioxidant and cytoprotective mechanisms of $M$. oleifera leaves on various renal cell types against APAP nephrotoxicity could be due to the presence of some vitamins [34]. However, several plants with antioxidant properties reported to prtotects against APAP nephrotoxic effects in different in vivo studies had been approved $[35,36]$. In the current study, aqueous extracts of $M$. oleifera leave significantly improved all blood values while no significant changes in MCV or MCHC. Similarly, the improvement in blood activity was noticed in rats when $M$. oleifera administrated orally due to its constituent which able to enhance hematopoiesis and/or might have an erythropoietin potential effects [37]. Hence, in kidney sections APAP caused severe changes in renal cells, following Moringa treatments the normal cellular architecture was retained and it in closer to the features of the control cells group. Furthermore, these findings are in line with another study of APAP renal toxicity in rats [21]. In view of the above findings, it is suggested that the phytochemical constituents in $M$. oleifera could contribute to it is antioxidant activity. Thus, the antioxidant effect of $M$. oleifera aqueous extract plays a significant role in amelioration of APAP induced renal damage.

\section{ACKNOWLEDGEMENT}

The Authors are grateful to the Research Centre, College of Veterinary Medicine and the Deanship of Scientific Research, University of Khartoum, Sudan for their care and supports; our deeply thankfulness goes to the specialist team at the Botany Unit of the Medicinal and Aromatic Plants Research Institute (MAPRI), Khartoum, Sudan.

\section{REFERENCES}

[1] R. Parmar, MPharm thesis: Nephroprotective activity of Indigofera aspalathoides Vahl on gentamicin induced nephrotoxicity in rats. Rajiv Gandhi University of Health Sciences, Karnataka, Bangalore. 2010.

[2] S. Ricksten, G. Bragadottir, B. Redfors, Renal oxygenation in clinical acute kidney injury. Critical Care Journal, 17, 2013, 221-230.

[3] A. Bougle, and J. Duranteau, Pathophysiology of sepsis-induced acute kidney injury: The role of global renal blood flow and renal vascular resistance. Contributions to Nephrology, 174, 2011, 89-97.

[4] D. Brown, and C. Wagner, Molecular mechanisms of acid-base sensing by the kidney. Journal of the American Society of Nephrology, 23, 2012, 774-780.

[5] D. Mahmood, and A. Waters, Comparative study of uranyl nitrate and cisplatin induced renal failure in rat. European Journal of Drug Metabolism and Pharmacokinetics, 19, 1994, 327-36.

[6] E. Begg, and M. Barclay, Aminoglycisides-50 years on. British Journal of Clinical Pharmacolog, 39, 1995, 597-603.

[7] R. Schnellman, Toxic responses of the kidneys. In: Casarett and Doull's Toxicology: The Basic Science of Poisons, McGraw-Hill Medical Division, New York, 2001, 491-514.

[8] A. Moyer, B. Fridley, G. Jenkins, A. Batzler, L. Pelleymounter, K. Krishna, Y. Ji, Y. Chai, K. Nordgren, anR. Weinshilboum, Acetaminophen-NAPQI hepatotoxicity: A cell line model system genome-wide association study. Toxicological Sciences, 120, 2011, 33-41.

[9] H. Jaeschke, C. Williams, M. McGill, Y. Xie, and A. Ramachandran, Models of drug induced liver injury for evaluation of phytotherapeutics and other natural products. Food Chem Toxicol, 55, 2013, 279-89.

[10] S. Syed, and A. Namdeo, Hepatoprotective effect of leaves of Erythroxylum monogynum Roxb, on paracetamol induced toxicity. Asian Pacific Journal of Tropical Biomedicine, 3, 2013, 877-881.

[11] A. Ghosh, and P. Sil, Anti-oxidative effect of a protein from Cajanus indicus L against acetaminopheninduced hepato-nephro toxicity. Journal of Biochemistry and Molecular Biology, 40, 2007, 1039-49.

[12] J. Fahey, Moringa oleifeira: A review of the medical evidence for its nutritional, therapuetic and prophylactic properties. Part I. Trees for Life Journal, 1, 2005, 5. 
[13] D. Jaiswal, P. Rai, A. Kumar, S. Mehta, and G. Watal, Effect of Moringa oleifera Lam. leaves aqueous extract therapy on hyperglycemic rats. Journal of Ethnopharmacology, 123, 2009, 392-6.

[14] F. Anwar, S. Latif, M. Ashraf, et al. (2007). Moringa oleifera: A food plant with multiple medicianl uses. Phytother Res 21, 2007, 17-25.

[15] D. Arora, J. Onsare, and H. Kaur, Bioprospecting of Moringa (Moringaceae): Microbiological perspective. Journal of Pharmacognosy and Phytochemistry, 1, 2013, 193-215.

[16] A. Shirwaikar, D. Issac, S. Malini, Effect of Aerva lanata on cisplatin and gentamicin model of acute renal failure. Journal of Ethnopharmcology, 90, 2014, 81-6.

[17] M. Lompo, and J. Dubois, Guissou, In vitro preliminary study of free radical scavenging activity of extracts from Khaya senegalensis A. Juss. (Meliaceae). Journal of Biological Science, 7, 2007, 677-80.

[18] H. Khalid, H. Elkamali, and A. Atta Elmanan, Trade of Sudanese natural medicinal and their role in human and wildlife health care. Cropwatch Newsletter, 10, 2007, 1-15.

[19] A. Verma, M. Vijayakumar, C. Mathela, C. Rao, In vitro and in vivo antioxidant properties of different fractions of Moringa oleifera leaves. Food and Chemical Toxicology, 47, 2009, 2196-201.

[20] N. Patel, B. Vrushabendra, P. Swamy, Evaluation of nephroprotective activity of Psidium Guajava Linn, leaves extract in paracetamol induced nephrotoxicity in rats. Research Journal of Pharmacutical Biological and Chemical Sciences, 3, 2012, 1247-56.

[21] Z. Abdul Hamid, S. Budin, N. Jie, A. Hamid, K. Husain, and J. Mohamed, Nephroprotective effects of Zingiber zerumbet Smith ethyl acetate extract against paracetamol-induced nephrotoxicity and oxidative stress in rats. Journal of Zhejiang University Science B, 13, 2012, 176-85.

[22] U. Reddy T, M. Lakshmi, S. Kumar, D. Kumar, Protective effect of Abutilon indicum L. (Malvaceae) against acetaminophen induced nephrotoxicity in rats. Journal of Life Science, 1, 2013, 40-43.

[23] K. Gopi, A. Reddy, K. Jyothi, and B. Kumar, Acetaminophen-induced hepato- and nephrotoxicity and amelioration by silymarin and Terminalia chebula in rats. Toxicology International, 17, 2010, 64-66.

[24] B. Parameshappa, M. Ali Basha, S. Sen, R. Chakraborty, G. Kumar, G. Sagar, L. Sowmya, K. Raju, P. Kumar, A. Lakshmi, Acetaminophen-induced nephrotoxicity in rats: Protective role of Cardiospermum halicacabum. Journal of Pharmacytical Biology, 50, 2012, 247-53.

[25] A. Vigila, and X. Baskaran, Nephroprotective activity of aqueous extract of Solanum nigrum in Amphotericin B induced Wister rats. International Journal of Applied Biology, 1, 2011, 14-21.

[26] P. Mayne, The kidneys and renal calculi. In: Clinical Chemistry in Diagnosis and Treatment, Edward Arnold Publications, London, 1994, 2-24.

[27] B. Ramadan, and M. Schaalan, The renoprotective effect of honey on paracetamol -induced nephrotoxicity in adult male albino rats. Life Science Journal, 8, 2011, 589-96.

[28] I. Abdel-Raheem, A. Abdel-Ghany, and G. Mohamed, Protective effect of quercetin against gentamicin induced nephrotoxicity in rats. Biological and Pharmacutical Bulletin, 32, 2009, 61-67.

[29] C. Abrass, Cellular lipid metabolism and the role of lipids in progresive renal disease. American Journal of Nephrology, 24, 2004, 46-53.

[30] R. Trevisan, R. Alessandro, and G. Lepore, Lipids and renal disease. Journal of the American Society of Nephrology, 17, 2006, 145-147.

[31] S. Sivakrishnan, and A. Kottaimuthu, Hepatoprotective activity of ethanolic extract of aerial parts of Albizia procera Roxb (Benth.) against paracetamol induced liver toxicity on Wistar rats. International Journal of Pharmacy and Pharmacutical Sciences, 6, 2014, 233-38.

[32] S. Sharifudin, S. Fakurazi, M. Hidayat, M. Hairuszah, M. Moklas, P. Arulselvan, Therapeutic potential of Moringa oleifera extracts against acetaminophen-induced hepatotoxicity in rats. Pharmacutical Biology, 51, 2013, 279-88.

[33] S. Fakurazi, I. Hairuszah, and U. Nanthini, Moringa oleifera Lam prevents acetaminophen induced liver injury through restoration of glutathione level. Food Chemistry andToxicololgy, 46, 2008, 2611-15.

[34] R. Estakhri, B. Hajipour, H. Majidi, H. Soleimani, Vitamin E ameliorates cyclophosphamide induced nephrotoxicity. Life Science Journal, 10, 2013, 308-13.

[35] G. Lakshmana, R. kumar, and P. Reddy, Determination of nephroprotective activity of ethanolic leaf extract of Moringa pterygosperma on paracetamol induced nephrotoxic rats. International Journal of Allied Medical Sciences and Clinical Research, 1, 2013, 51-61.

[36] V. Srinivasan, R. Panneerselvam, and S. Gunasekaran, Ethanolic extract of Melia azadirachta against acetaminophen induced nephrotoxicity. International Journal of Pharm Tech Research, 6, 2014, 70-79.

[37] O. Ujah, I. Ujah, and J. Johnson, Effect of ethanolic leaf extract of Moringa olifera leaf on haematological and biochemical parameters of Wistar rats. Journal of Natural Product and Plant Resources, 3, 2013, 10-14. 

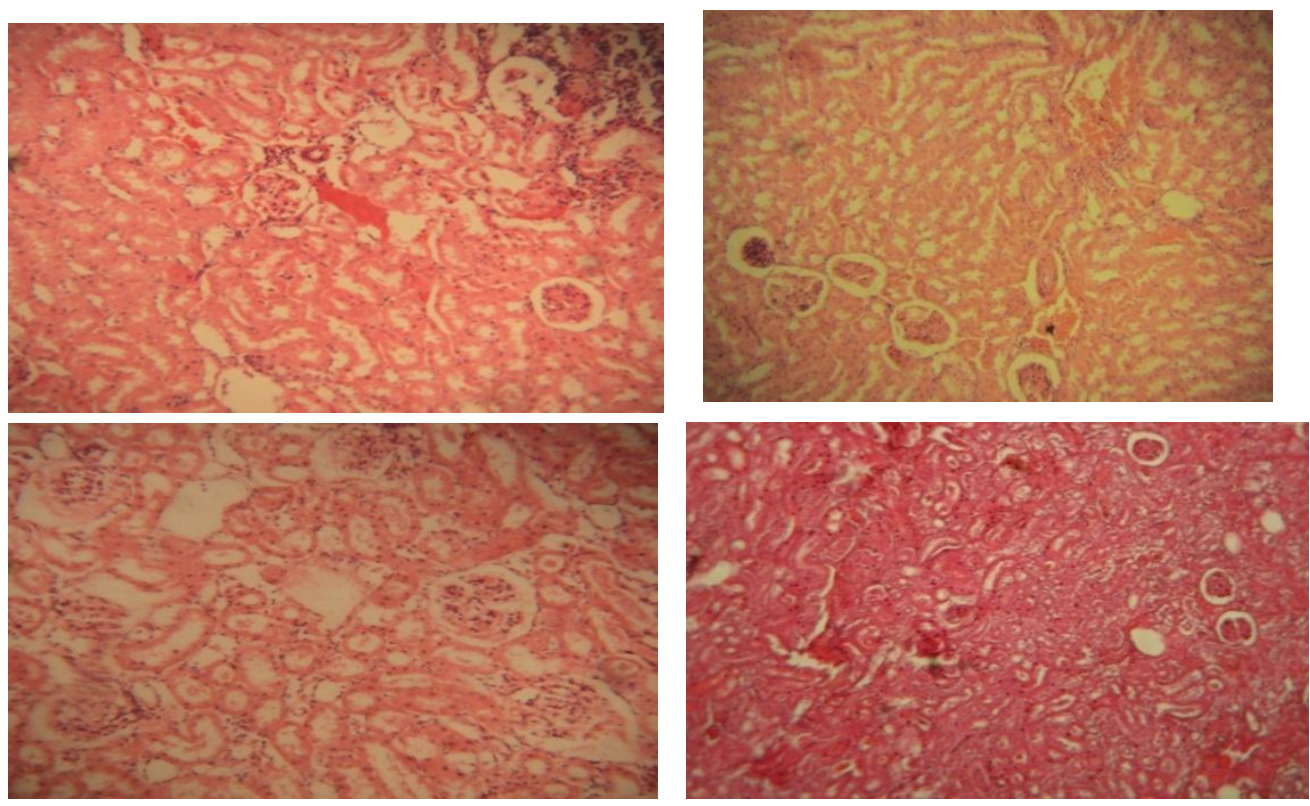

Figure 1. Kidney cells of rats treated with $M$. oleifera (MO) aqueous extract and acetaminophen (APAP) (H\&E

X100). (a) Severe hemorrhage, congestion, shrinking of the glomeruli with necrosis of tubules, infiltration of inflammatory cells (APAP $200 \mathrm{mg} / \mathrm{kg}$ ). (b) Slight hemorrhage and congestion and infiltration of inflammatory in the glomeruli (MO $250 \mathrm{mg} / \mathrm{kg}+$ APAP $200 \mathrm{mg} / \mathrm{kg}$ ). (c) Slight fatty change and infiltration of inflammatory cells in the glomeruli and tubules (MO $500 \mathrm{mg} / \mathrm{kg}+$ APAP $200 \mathrm{mg} / \mathrm{kg}$ ). (d) Slight congestion with intact glomeruli (MO $1000 \mathrm{mg} / \mathrm{kg}+$ APAP $200 \mathrm{mg} / \mathrm{kg}$ ).

Table 1. Biochemical changes in rats treated with aqueous extracts of M. oleifera (MO) leaves on nephrotoxicity induced by acetaminophen (APAP).

Means in the same column with the same letter are not significant different $(P<0.05)$.G1= Control, G2= APAP

\begin{tabular}{lcccccc}
\hline $\begin{array}{l}\text { Grou } \\
\mathbf{p}\end{array}$ & $\begin{array}{l}\text { Parameter } \\
\mathbf{s} \\
\text { Creatinine } \\
(\mathbf{m g} / \mathbf{d l})\end{array}$ & $\begin{array}{c}\text { Urea } \\
(\mathbf{m g} / \mathbf{d l})\end{array}$ & $\begin{array}{c}\text { Cholesterol } \\
(\mathbf{m g} / \mathbf{d l})\end{array}$ & $\begin{array}{c}\text { T. Lipids } \\
(\mathbf{m g} / \mathbf{d l})\end{array}$ & $\begin{array}{c}\text { T. Protein } \\
(\mathbf{g} / \mathbf{d l})\end{array}$ & $\begin{array}{c}\text { Albumin } \\
(\mathbf{g} / \mathbf{d l})\end{array}$ \\
\hline $\mathbf{G 1}$ & $0.69 \pm 0.03^{\mathbf{c}}$ & $45.11 \pm 8.53^{\mathbf{c d}}$ & $49.79 \pm 4.24^{\mathbf{b}}$ & $180.21 \pm 11.46^{\mathbf{b}}$ & $6.42 \pm 0.47^{\mathbf{a}}$ & $3.47 \pm 0.22^{\mathbf{a}}$ \\
$\mathbf{G 2}$ & $1.54 \pm 0.17^{\mathbf{a}}$ & $101.31 \pm 2.47^{\mathbf{a}}$ & $62.22 \pm 3.26^{\mathbf{a}}$ & $266.13 \pm 6.22^{\mathbf{a}}$ & $4.23 \pm 0.23^{\mathbf{c}}$ & $2.44 \pm 0.12^{\mathbf{b}}$ \\
$\mathbf{G 3}$ & $0.95 \pm 0.02^{\mathbf{b}}$ & $87.03 \pm 4.69^{\mathbf{b}}$ & $52.81 \pm 2.47^{\mathbf{b}}$ & $192.73 \pm 4.99^{\mathbf{b}}$ & $5.33 \pm 0.17^{\mathbf{b}}$ & $2.86 \pm 0.13^{\mathbf{b}}$ \\
$\mathbf{G 4}$ & $0.66 \pm 0.14^{\mathbf{c}}$ & $48.71 \pm 3.45^{\mathbf{c}}$ & $36.36 \pm 2.68^{\mathbf{c}}$ & $177.41 \pm 10.67^{\mathbf{b c}}$ & $7.20 \pm 0.18^{\mathbf{a}}$ & $3.54 \pm 0.25^{\mathbf{a}}$ \\
$\mathbf{G 5}$ & $0.80 \pm 0.03^{\mathbf{b c}}$ & $62.22 \pm 1.21^{\mathbf{c}}$ & $38.25 \pm 3.43^{\mathbf{c}}$ & $159.60 \pm 5.08^{\mathbf{c}}$ & $6.89 \pm 0.32^{\mathbf{a}}$ & $3.94 \pm 0.10^{\mathbf{a}}$ \\
\hline
\end{tabular}

(200 mg/kg), G3= APAP $200 \mathrm{mg} / \mathrm{kg}+$ MO $250 \mathrm{mg} / \mathrm{kg}, \mathrm{G} 4=$ APAP $200 \mathrm{mg} / \mathrm{kg}+\mathrm{MO} 500 \mathrm{mg} / \mathrm{kg}$, G5 = APAP $200 \mathrm{mg} / \mathrm{kg}+$ MO $1000 \mathrm{mg} / \mathrm{kg}$. Symbols for the difference between the groups $(\mathbf{a}, \mathbf{b}, \mathbf{c})=$ Mean values within the same row bearing different superscripts are significantly different at $P<0.05$.

Table 2. Hematological changes in rats treated with aqueous extracts of $M$. oleifera (MO) leaves on nephrotoxicity induced by acetaminophen (APAP).

\begin{tabular}{|c|c|c|c|c|c|c|}
\hline \multirow{2}{*}{$\begin{array}{l}\text { Grou } \\
\text { p }\end{array}$} & \multicolumn{6}{|c|}{ Parameters } \\
\hline & $\begin{array}{c}\text { RBCs } \\
\left(10^{6} / \mu \mathrm{L}\right)\end{array}$ & $\begin{array}{c}\mathrm{Hb} \\
(\mathrm{g} / \mathrm{dl})\end{array}$ & $\begin{array}{r}\text { PCV } \\
(\%)\end{array}$ & $\begin{array}{l}\text { MCV } \\
\text { (fl) }\end{array}$ & $\underset{(\mathbf{p g})}{\mathrm{MCH}}$ & $\begin{array}{l}\mathrm{MCHC} \\
(\mathrm{g} / \mathrm{dl})\end{array}$ \\
\hline G1 & $8.01 \pm 0.14^{\mathrm{a}}$ & $14.03 \pm 0.39^{b}$ & $44.42 \pm 0.76^{\mathrm{a}}$ & $55.62 \pm 1.61^{b}$ & $17.18 \pm 0.49^{c}$ & $31.50 \pm 1.38^{\mathrm{a}}$ \\
\hline G2 & $6.19 \pm 0.28^{c}$ & $12.05 \pm 0.40^{\mathrm{c}}$ & $36.80 \pm 0.94^{\mathrm{c}}$ & $60.75 \pm 1.36^{\mathrm{a}}$ & $19.93 \pm 0.57^{\mathrm{a}}$ & $32.90 \pm 0.79^{\mathrm{a}}$ \\
\hline G3 & $7.49 \pm 0.30^{b}$ & $13.77 \pm 0.47^{\mathrm{b}}$ & $40.78 \pm 0.83^{b}$ & $53.97 \pm 0.87^{\mathrm{b}}$ & $18.62 \pm 0.16^{\mathrm{b}}$ & $34.07 \pm 0.96^{\mathrm{a}}$ \\
\hline G4 & $8.10 \pm 0.51^{\mathrm{a}}$ & $15.75 \pm 0.52^{\mathrm{a}}$ & $45.04 \pm 1.35^{\mathrm{a}}$ & $55.63 \pm 1.15^{\mathrm{b}}$ & $18.30 \pm 0.38^{\mathrm{bc}}$ & $32.20 \pm 0.88^{\mathrm{a}}$ \\
\hline G5 & & & & & & \\
\hline
\end{tabular}




\begin{tabular}{|c|c|c|c|c|c|}
\hline $\begin{array}{l}8.78 \\
\pm 0.32^{\mathrm{a}}\end{array}$ & $14.62 \pm 0.58^{\mathrm{ab}}$ & $42.60 \pm 1.12^{\mathrm{ab}}$ & $48.65 \pm 0.72^{\mathrm{c}}$ & $16.70 \pm 0.48^{\mathrm{c}}$ & $34.89 \pm 0.69^{\mathrm{a}}$ \\
\hline
\end{tabular}

Means in the same column with the same letter are not significant different $(P<0.05)$.G1= Control, G2= APAP (200 mg/kg), G3= APAP $200 \mathrm{mg} / \mathrm{kg}+$ MO $250 \mathrm{mg} / \mathrm{kg}, \mathrm{G} 4=$ APAP $200 \mathrm{mg} / \mathrm{kg}+$ MO $500 \mathrm{mg} / \mathrm{kg}, \mathrm{G} 5=$ APAP $200 \mathrm{mg} / \mathrm{kg}+$ MO $1000 \mathrm{mg} / \mathrm{kg}$. Symbols for the difference between the groups $(\mathbf{a}, \mathbf{b}, \mathbf{c})=$ Mean values within the same row bearing different superscripts are significantly different at $P<0.05$. 